\title{
BIBLIOGRAFÍA SOBRE TEMAS ÁRABES DE LAS BALEARES
}

\author{
Por \\ FRANCISCO FRANCO SÁNCHEZ
}

\section{PRESENTACIÓN}

La finalidad de las recopilaciones bibliográficas es muy diversa, según lo que en ellas vayamos buscando. Se podrían comparar con un cajón de sastre en el cual lo ideal sería que cada uno pudiera hallar precisamente lo que busca: el investigador poder mantenerse al día de lo que se va publicando y tener a mano todo lo editado anteriormente, el estudiante poseer una herramienta que le ayude en su trabajo como introductora en un mundo que aún no conoce bien, para todos un amplio fichero consultable en cualquier momento como útil guía por unos caminos que sólo el tiempo nos permiten llegar a conocer bien, y siempre nos puede servir de ayuda a la hora de completar datos de cualquier referencia bibliográfica.

Estos propósitos son los que albergaba la primera gran recopilación bibliográfica que supone el libro de M. de Epalza, M. J. Paternina y A. Couto sobre Moros y Moriscos en el Levante Peninsular (Sharq Al-Andalus). Introducción Bibliográfica, (Alicante, Instituto de Estudios Alicantinos, 1983), que se ceñia a la larga presencia musulmana en el espacio geográfico que el título del mismo indica. Esta recopilación tiene su continuación en la revista Sharq Al-Andalus. Estudios Árabes, que en su Sección Bibliográfica pretende ir subsanando las posibles carencias que el libro anterior pudiera tener, al mismo tiempo que está dando a conocer los nuevos estudios que se van publicando. Esto es lo que se ha pretendido hacer en los números 1 y 2 de dicha revista, en cuyo volumen primero se dedicó atención preferente a los estudios árabes que conciernen al territorio murciano, mientras que en el tercero de los números se ha hecho lo propio con los estudios referentes a las Baleares y Cataluña

En las $V$ Jornades d'Estudis Històrics Locals (Palma de Mallorca, del 28 al 30 de diciembre de 1985), en el texto de una breve comunicación que titulamos «Por una Bibliografía de estudios árabes baleáricos», intentamos hacer una sistematización y breve estudio crítico de las numerosas investigaciones que han tenido como fin el pasado árabe baleárico (temas tratados, medios de difusión de los estudios, lagunas, etc.l. El mismo bien pudiera servir como introducción al presente trabajo, 
que por otra parte es el lógico complemento del anterior, puesto que el material bibliográfico, que en dicha comunicación únicamente se menciona, tiene su plasmación y desarrollo en la presente Bibliografía.

Hemos recogido en las siguientes páginas unos 740 títulos diversos sobre los más variados asuntos. Deseamos que sirvan para sentar las bases de otra más amplia recopilación que recoja los muchos trabajos que faltan, puesto que, aunque cabría afirmar que las más relevantes aportaciones a los mencionados estudios están recogidas, sí faltan muchos trabajos puntuales, o sería necesario completar datos de algunas fichas imperfectas. Una bibliografía de este tipo siempre será una propuesta lcomo lo sugiere el título de nuestra comunicación a las mencionadas Jornadasl, por la peculiaridad que tienen estas recopilaciones: la continua necesidad de ser completadas con las nuevas aportaciones que se van publicando continuamente. Por lo que, contando con esta limitación, hacemos votos por la creación de ese Corpus Bibliográfico de estudios árabes baleáricos - que se integrara a su vez dentro de ese soñado Corpus Bibliográfico General de estudios árabes, que no pasa de ser un proyecto en la actualidad-, fines a los que modestamente nuestra revista Sharq Al-Andalus. Estudios Árabes pretende ir contribuyendo poco a poco.

La presente publicación es el resultado de un largo proceso de recogida de fichas bibliográficas, y somos conscientes de que faltan aún muchos trabajos para completar esta Bibliografía (más por propio despiste o dificultad de acceso a los mismos que por cualquier otra razón. Deseamos que sea una contribución a la recopilación y difusión de trabajos del pasado, algunos quizá olvidados, pero útiles en lo que tienen de pervivencia o porque en ellos es posible ver, comparándolos con los estudios más recientes, la evolución del pensamiento y la investigación en un período de tiempo más o menos cercano a nosotros. Igualmente desearíamos sirviera para la difusión de trabajos más actuales, en muchos casos de gran interés, pero que por estar publicados en medios de escasa tirada o de poca difusión pasan desapercibidos para la mayoría, si exceptuamos a unos pocos que tienen acceso a estos trabajos. De ahí el gran interés de las bibliografías como instrumento de difusión, ayuda a la investigación, y como archivo cultural al servicio del estudioso, o del historiógrafo, para los que pueden ser de gran utilidad.

El criterio de sistematización podría parecer un tanto difuso porque no nos restringimos al estricto dominio político musulmán, y hay referencias también contemporáneas. Para aclarar esto diremos que se han reseñado los trabajos que tratan: del período de dominio político de los musulmanes, de la conquista cristiana y sus diferentes documentos (Repartimento, etc.), del perído de dominio cristiano en el cual los musulmanes, primero - como mudéjares - eran un grupo social mayoritario, y luego, como meros esclavos, pasaron a ser minoría en la Edad Moderna, en la que además de este fenómeno de los esclavos musulmanes nos hemos fijado en el de la piratería islámica proveniente del norte de África. En las épocas sucesivas hemos creído conveniente recoger los trabajos que hagan referencia a las Baleares y sus relaciones de diversa índole con el mundo islámico. Además de otros muchos estudios de índole cultural, social, económica, arqueológica, política, etc., que se encuadren u ocupen de estos períodos cronológicos. Igualmente se han recogido los trabajos más generales en los que se halle referencia a las islas, bien de geógrafos árabes (descripciones geográficas), o literatos, científicos y demás personajes musulmąnes, de tratados islámicos medievales, o de fuentes cristianas que las mencionen y nos muestren la huella o legado de lo árabe.

Finalmente decir como colofón que este trabajo desearía ser una aportación a un campo, como el bibliográfico, no muy abundado por los investigadores, alegando 
al mismo tiempo por una prodigalidad mayor de los mismos hacia él, esperando sea ese instrumento antes mencionando y deseando tenga pronta continuación.

No podemos finalizar estas líneas sin agradecer sinceramente la ayuda prestada en la recogida de datos por Magdalena Riera Frau y Jaume Serra Barceló, y a todos los demás que han contribuido a su elaboración, especialmente a Míkel de Epalza, sin los cuales esta sistematización no hubiera visto su forma, definitiva.

LLos 730 trabajos de la bibliografía se encuentran, con esta introducción, en un librito separado de esta revista, dentro de la colección SHARQ AL-ANDALUS. ESTUDIOS ÁRABES, Suplementos Bibliográficos, vol. 2.) 